\title{
INFLUENCE OF STRUCTURAL FEATURES AND FRACTURE PROCESSES ON SURFACE ROUGHNESS: A CASE STUDY FROM THE KROSNO SANDSTONES OF THE GÓRKA-MUCHARZ QUARRY (LITTLE BESKIDS, SOUTHERN POLAND)
}

\author{
ŁUKASZ PIECZARA \\ University of Warsaw, Faculty of Geology, Department of Geomechanics, Warsaw, Poland. \\ E-mail: lukasz.pieczara@student.uw.edu.pl
}

\begin{abstract}
The paper presents the results of analysis of surface roughness parameters in the Krosno Sandstones of Mucharz, southern Poland. It was aimed at determining whether these parameters are influenced by structural features (mainly the laminar distribution of mineral components and directional distribution of non-isometric grains) and fracture processes. The tests applied in the analysis enabled us to determine and describe the primary statistical parameters used in the quantitative description of surface roughness, as well as specify the usefulness of contact profilometry as a method of visualizing spatial differentiation of fracture processes in rocks. These aims were achieved by selecting a model material (Krosno Sandstones from the Górka-Mucharz Quarry) and an appropriate research methodology. The schedule of laboratory analyses included: identification analyses connected with non-destructive ultrasonic tests, aimed at the preliminary determination of rock anisotropy, strength point load tests (cleaved surfaces were obtained due to destruction of rock samples), microscopic analysis (observation of thin sections in order to determine the mechanism of inducing fracture processes) and a test method of measuring surface roughness (two- and three-dimensional diagrams, topographic and contour maps, and statistical parameters of surface roughness). The highest values of roughness indicators were achieved for surfaces formed under the influence of intragranular fracture processes (cracks propagating directly through grains). This is related to the structural features of the Krosno Sandstones (distribution of lamination and bedding).
\end{abstract}

Key words: anisotropy, rock cracking, fracture processes, flysch, geomechanics, Krosno Sandstones, surface roughness

\section{INTRODUCTION}

Investigation of surface textures is usually accomplished on several levels: macroscopic (including waviness and other surface defects), microscopic (surface roughness) and submicroscopic (very minor surface irregularities).

Surface roughness is a morphological feature of a solid that is not a result of its shape, but is at least an order of magnitude smaller. In sciences such as metrology or mechanics many statistical indicators are used in a quantitative evaluation of surface roughness. The magnitude of roughness on a rock surface depends, among other conditions, on the mineral composition, fracture processes and diagenetic or tectonic factors [11].

Rock destruction, as a result of cracking processes, is based on the rapid spread of fractures. This process is facilitated by the existence of inhomogeneous fragments in the internal structure (structural defects).
With increasing load, they cause the appearance of stresses exceeding the strength of structural bonds. Crack propagation depends on the direction of external forces, rock origin, and also on the nature of defects in the internal structure [7]. Particularly important factors include: shape, strength and directional arrangement of mineral grains, lamination, nature of the matrix, and the geometric distribution of pore space. Fracture processes are determined by all these properties [9].

There are three basic types of fractures in rocks: intragranular, intergranular, and transgranular. These types differ in factors that cause crack formation, types of structural elements that are involved in the propagation, intensity of the process, and subsequent residual strength [10].

An intragranular fracture is caused by stretching of single mineral grains. This type of fracture refers to rocks that are characterized by a regular, granular and compact mineral composition and a strong matrix. Rocks with a random dispersion of mineral grains 
(irregular shapes) and with a weak matrix are characterized by an intergranular fracturing process dominated by shear. Therefore changes in crack propagation directions may occur in the rocks as a result of the presence of preferential fracture planes (different arrangement of atoms in the lattice of individual grains).

In summary, the process of destruction is an individual feature of the rock, depending on the mineral composition, origin, and internal structure. Therefore, to predict the impact of the internal structure and fracture processes on surface roughness, it is important to determine directions of microcrack propagation and the structural conditions at which preferential fracture planes form, thus accelerating rock degradation.

\section{OBJECT AND PURPOSES OF RESEARCH}

Tests characterizing the impact of structural features and fracture processes on surface roughness were performed on samples of the Krosno Sandstones, collected in the Górka-Mucharz Quarry, located in the eastern part of the Little Beskids in southern Poland (Fig. 1).

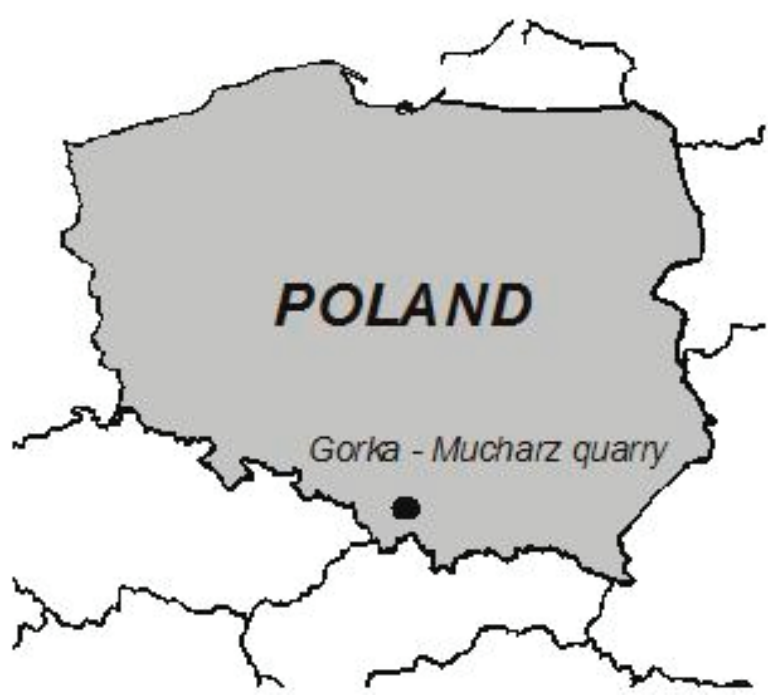

Fig. 1. Location of the Górka-Mucharz Quarry

The age of the Krosno Sandstones from the Górka-Mucharz Quarry has been determined as the Oligocene. The sandstones occur as coarse-bedded strata with thicknesses of $0.5-10 \mathrm{~m}$. The samples were taken from sub-cubical blocks collected in the quarry, with side lengths of approximately $30 \mathrm{~cm}$.
They were cut out taking into consideration macroscopically determined structural features. The Krosno Sandstones from the Górka-Mucharz Quarry are bluegrey in colour, which changes to yellow-brown on weathered rock.

In the analysed samples, two specific features are visible in macroscopic scale: a laminar distribution of the mineral components in compliance with bedding and directions of non-isometric grains. The laminar structure is emphasised by dark iron compounds, and the rock texture can be described as directional and containing various micas and dark minerals.

Petrographic analysis confirmed the macroscopic observations with regard to the directional arrangement of the minerals. The texture of the samples analysed can be described as slightly directional, emphasized by feldspars and opaque minerals. The matrix is clay-carbonate with fine quartz, and the sorting is good. There are also lithoclasts of metamorphic and carbonate rocks, as well as numerous dark- and lightcoloured feldspars. The mineral grains are relatively smooth, which indicates a small distance between the sedimentary area and the alimentation area. Sporadically there occur single grains of non-weathered glauconite, which indicates slight diagenesis of the rock material. Based on the mineral composition, the rocks can be classified as medium-grained lithic wackes or arcose wackes with an even content of feldspars and lithoclasts and a slightly directional texture with numerous bright and dark mica flakes [5], [9].

The main purpose of the study was to determine whether the structural features (mainly laminar distribution of the mineral components and directional distribution of non-isometric grains) and fracture processes have impact on the parameters of surface roughness. The tests enabled us to determine and describe the primary statistical parameters used in the quantitative description of surface roughness, as well as specify the usefulness of contact profilometry as a method of visualizing spatial differentiation of fracture processes in rocks.

These aims were achieved by choosing a model anisotropic rock material and a proper research methodology.

\section{METHODOLOGICAL ASSUMPTIONS}

The research schedule comprised five basic stages. The first stage included identification of the samples, i.e., macro- and microscopic analysis, with particular attention drawn on the characteristic features of the 
internal structure. Moreover, the samples were oriented in accordance to bedding, lamination and longer mineral axes. Such processed samples were given identification codes characterizing the orientation of the sample axes in relation to the structural features of the rock samples:

- " $T$ " - axis of the sample perpendicular to lamination,

- "F" - axis of the sample parallel to lamination and parallel to the longer mineral axes,

- "L" - axis of the sample parallel to lamination and perpendicular to the longer mineral axes.

Further, the samples were marked with three main analysed directions and oriented in relation to the imposed fracture planes. As a result, a system of three perpendicular planes was obtained; the planes were also oriented in relation to the structural features of the rock medium (Fig. 2).

Apart from the main directions being analysed, the measurements were densified along six additional axes located on the circumference of the sample. This mode of preparing the samples allowed the diverse orientation of structural features to be preserved in relation to the directions analysed in each sample.

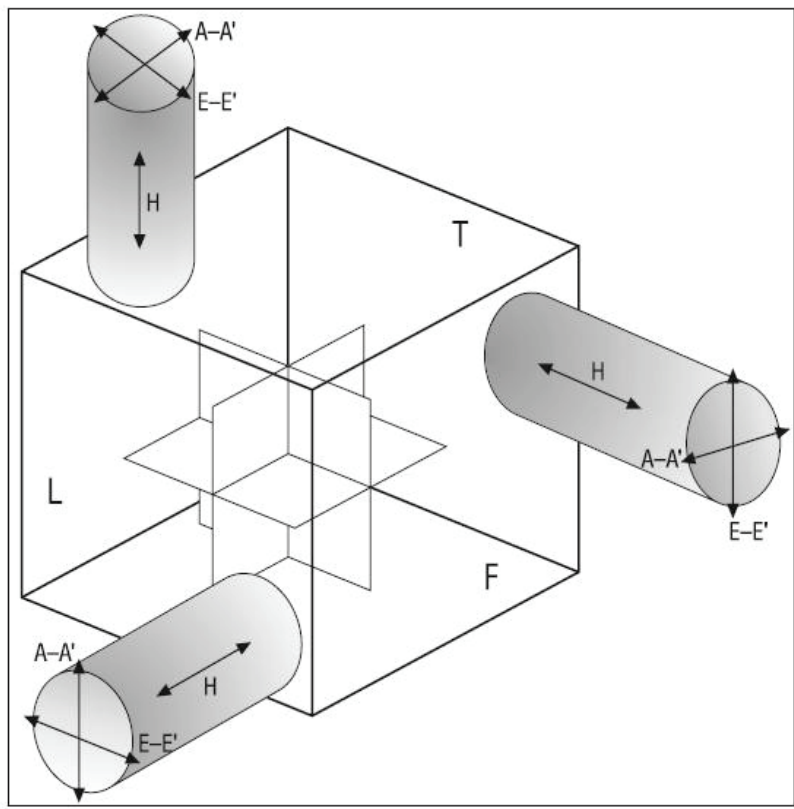

Fig. 2. The orientation of the sample axes in relation to the structural features of the rock medium

The second stage included non-destructive ultrasonic tests. These were aimed at determining the influence of structural features on the velocity of ultrasonic wave propagation (assessment of anisotropy of wave velocity propagation, indication of privileged directions). High variability of the rock internal struc- ture causes that ultrasonic waves within a single sample may propagate with a variable velocity [1], [2], [8], [12]. Therefore, it is important for the ultrasonic tests to be conducted on oriented rock samples. Acoustic properties of the Krosno Sandstones from Mucharz were analysed using the transfer method. It was based on direct measurement of time at which the impulse passes through the rock sample with normalized dimensions, between the transmitter and receiver heads, in accordance with the imposed fracture planes. In the case of each of the six (two representing each group) analysed samples, nine measurements of the longitudinal wave velocity $\left(V_{\mathrm{P}}\right)$ were conducted along earlier marked directions ( 8 along the circumference at $1 / 4$ of the sample height, one along the axis). The next stage included resistance tests, conducted with application of a manual press, used to make point load tests. Because of the dimensions of the samples, an axis test was applied. Cleaved planes obtained after point load tests were next used in the analysis of surface roughness.

The identification, ultrasonic and resistance tests were an introduction to the basic analyses that were focused on determining the influence of structural features and fracturing characteristics and course on surface roughness of the Krosno Sandstones from Mucharz. The influence of the internal structure and structural features in the course of fracturing processes was investigated in thin sections with application of microscopic analysis in transmitting light; the thin sections were additionally coloured. In this case, penetration of the colouring agent between the mineral grains allowed a better exposure of the fracture course and the nature of its margins. Moreover, observations of thin sections allowed us to determine the mechanism that induced the fracturing processes, their course and characteristics of the properties of the propagating fracture. Application of polarizing microscope and dedicated software enabled tracing, e.g., the morphology of the contact surfaces, direction of fracture propagation, its geometric parameters and the course of its margins.

Surface roughness was determined in representative samples using the contact profilometer Hommel Tester 8000 (Fig. 3a), produced by Hommel Werke, with Turbo Roughness software. A set of technical parameters describing the profilometer are presented in Table 1.

The method is based on the movement (usually with a constant velocity) of a measuring head of the profilometer towards the direction of the measured profile. The imaging blade mounted in the measurement head contacts with the surface of the analysed 
sample due to stress. The converter in the profilometer transforms the changes in the relative position of the imaging blade and the remaining parts of the measuring head, which correspond to surface roughness of the sample, into an electric signal. After amplification, the signal is filtered by removing deviations caused by shape and waviness. Next the signal is registered and elaborated to determine the values of the given parameter. In order to interpret the influence of structural features and the fracturing process of surface roughness in the Krosno Sandstones from Mucharz, roughness analysis of surfaces was conducted on 6 samples (2 per each earlier assumed fracturing planes).

Table 1. Hommel Tester 8000 - technical specifications [www.metrology-direct.com]

\begin{tabular}{|c|c|}
\hline $\begin{array}{l}\text { Measuring ranges/ } \\
\text { Resolution }\end{array}$ & $\begin{array}{l} \pm 8 \mu \mathrm{m} / 1 \mathrm{~nm} \\
\pm 80 \mu \mathrm{m} / 10 \mathrm{~nm} \\
\pm 800 \mu \mathrm{m} / 100 \mathrm{~nm} \\
\pm 8000 \mu \mathrm{m} / 1000 \mathrm{~nm}\end{array}$ \\
\hline Cut-offs & $\begin{array}{l}0.025 / 0.08 / 0.25 / 0.8 / 2.5 / 8.0(\mathrm{~mm}) \\
\text { selectable }-2 \text { to }+1 \text { cut-off steps } \\
\text { individual } 0.001 \text { to } 80 \text { in } 0.001 \\
\text { increments }\end{array}$ \\
\hline Tracing speed $[\mathrm{Vt}]$ & $\begin{array}{l}\text { lt }-0.05 / 0.15 / 0.5 \mathrm{~mm} / \mathrm{s} \text { or variable } \\
0.01-2.0 \mathrm{~mm} / \mathrm{s} \text { in } 0.01 \text { increments }\end{array}$ \\
\hline Tracing length [lt] & $\begin{array}{l}0.48 / 1.5 / 4.8 / 15 / 48 \mathrm{~mm} \text { or variable } \\
0.1-200 \mathrm{~mm}\end{array}$ \\
\hline Measuring length [lm] & $0.40 / 1.25 / 4.0 / 12.5 / 40 \mathrm{~mm}$ or variable \\
\hline Cut-off $[\lambda]$ & $0.08 / 0.25 / 0.8 / 2.5 / 8.0 \mathrm{~mm}$ \\
\hline $\begin{array}{l}\text { Pressure of the } \\
\text { measuring tip }\end{array}$ & $0.6-2 \mathrm{mN}$ \\
\hline
\end{tabular}

Initially, a macroscopic analysis of the sample surface was conducted to determine the representative field of analysis. Next, the sample was mounted on

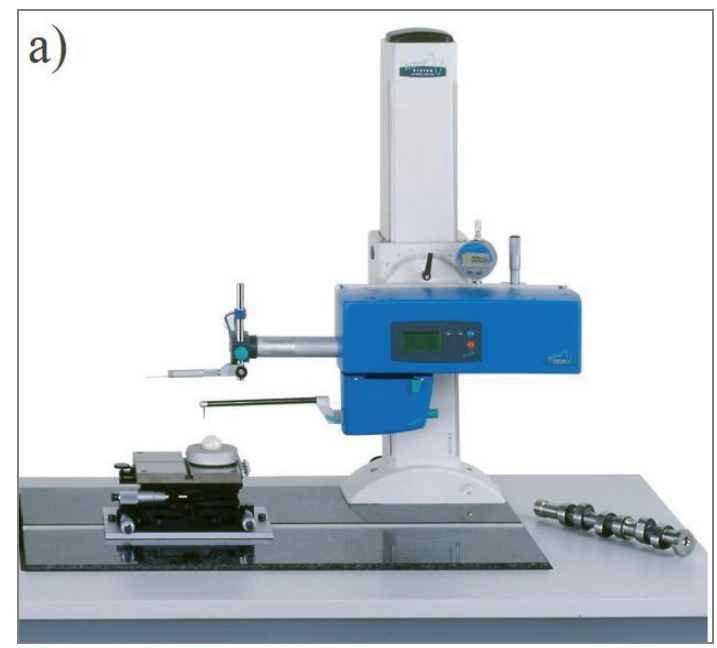

a tripod and an analysis field was marked, i.e., a square with side length of $30 \mathrm{~mm}$. The starting point of the analysis and the direction of head movement were also marked (Fig. 3b).

In the next stage, profilometer software was configured to modify to the conditions of the analysis. The measurements were made with a vertical (-) and horizontal $(x, y)$ digitizing step of $2.5 \mu \mathrm{m}$, and the velocity at which the imaging blade moved along the analyzed profile was $0.5 \mathrm{~mm} / \mathrm{s}$. Data collected during the analysis were visualized and elaborated using HommelMap Basic software. Thus, it was possible to create topographic maps, contour maps, 2D and 3D diagrams, as well as determine the statistical parameters that characterize surface roughness (Fig. 4). The arithmetic mean of the absolute values of roughness $\left(S_{\mathrm{a}}\right)$ is the distance between two parallel planes that are sides of a cuboid, whose base has a length equal to the length of the measured profile. The value of this parameter is not sensitive to single large peaks and cavities in the profile due to the fact that absolute values are used in the formula. A parameter that is more sensitive to single peaks and cavities in the profile under study is the root mean squares of roughness deviation $\left(S_{\mathrm{q}}\right)$. The next parameter analysed is roughness kurtosis $\left(S_{\mathrm{ku}}\right)$. It supplements the quantitative characteristics of the roughness surface. This indicator is particularly sensitive to large peaks and cavities in the profile. It measures the distribution dip of attenuation density of the profile elevation values, thus is the measure of the curve sharpness. A sharp curve is a curve that has large, sharp peaks and deeply incised cavities. A flat curve of attenuation density refers to a curve with numerous small and gentle peaks and a large number of rounded cavities. Parameter $S_{p}$

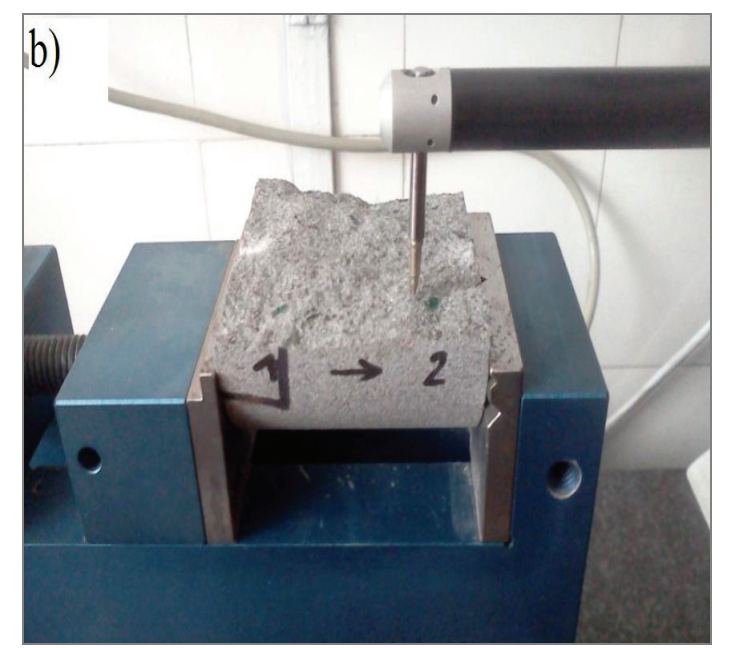

Fig. 3. (a) Contact profilometer Hommel Tester 8000 produced by Hommel Werke;

(b) The rock sample mounted on a profilometer tripod 


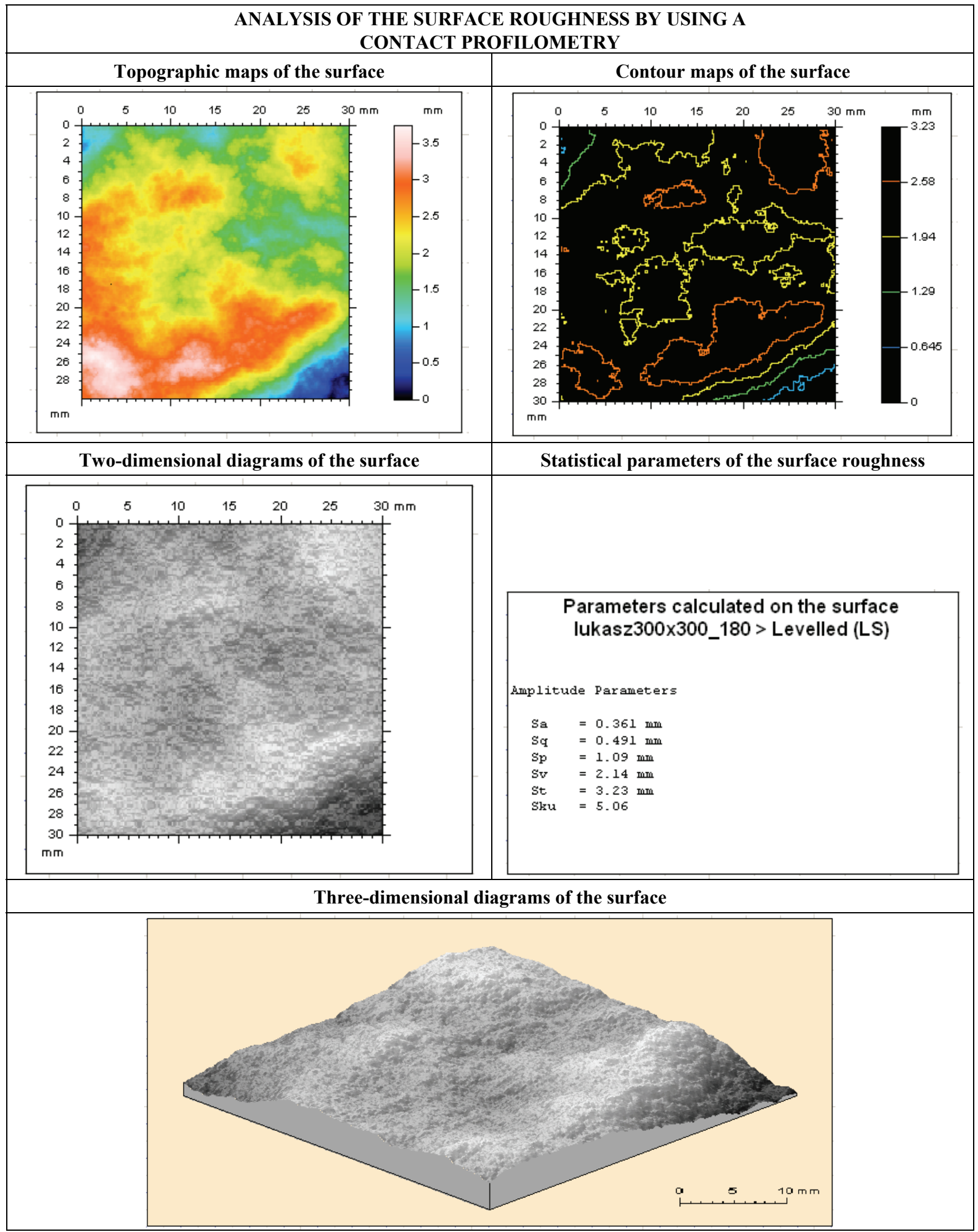

Fig. 4. Varied examples of visualization of the data collected from the cleaved surfaces

is the value of the highest profile elevation values. This index determines the highest elevation value of the analysed surface; a high value of this parameter indicates the presence of sharp peaks on the surface, whereas a low value informs of the presence of wide peaks (plateau). A similar case occurs with the depth of the deepest valley $S_{\mathrm{v}}$ on the analysed surface. The parameter $S_{\mathrm{t}}$ is the sum of the highest peak and the deepest cavities on the surface (total height of the roughness surface). 


\section{RESULTS}

Velocities of the longitudinal wave $\left(V_{\mathrm{p}}\right)$ measured along the accepted directions indicate the presence of anisotropy of internal structure in the analysed material. The analysis shows that the values are very variable. The velocity of the longitudinal wave is from $3644 \mathrm{~m} / \mathrm{s}$ to $4483 \mathrm{~m} / \mathrm{s}$. The $V_{\mathrm{p}}$ values have a bi-modal distribution on a histogram. The maxima reach 3800 and $4300 \mathrm{~m} / \mathrm{s}$, respectively. Contribution of the second value is 3 times larger.

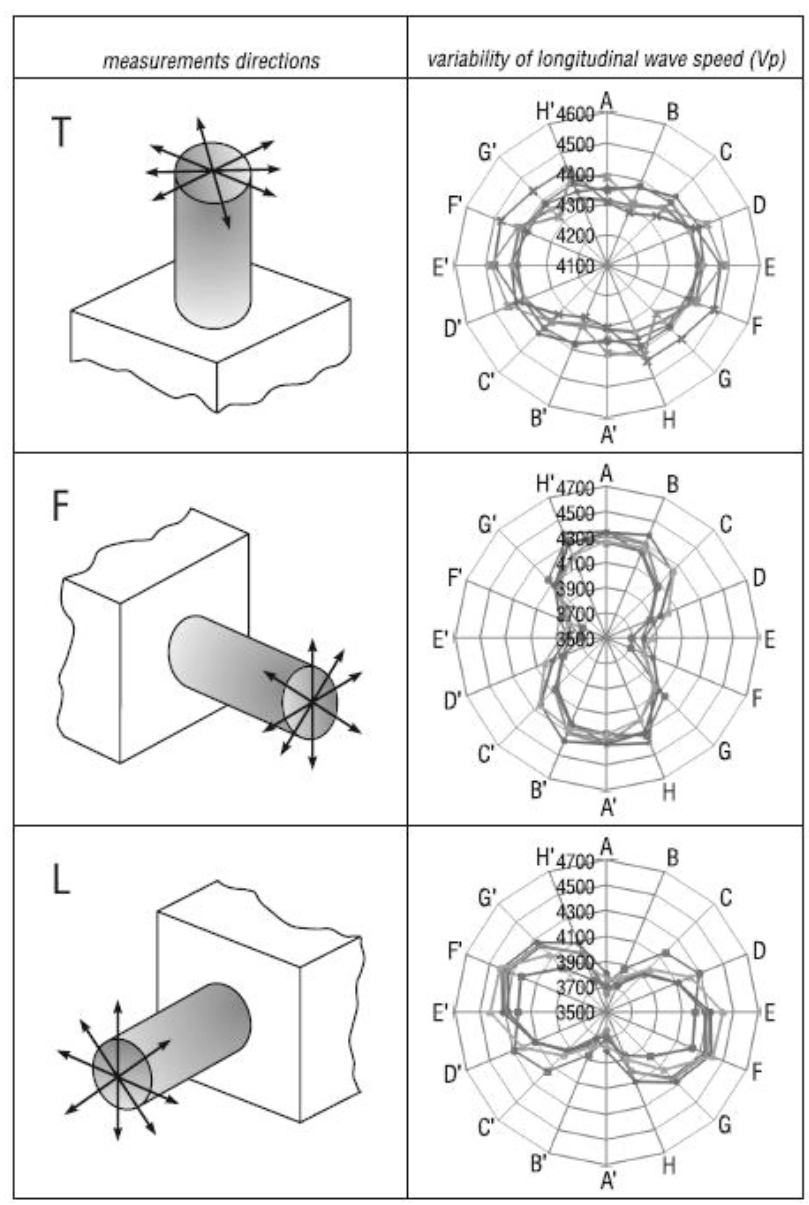

Fig. 5. Variability of longitudinal wave speed $\left(V_{\mathrm{p}}\right)$ analysed in relation to the accepted research directions

A unified schedule of research directions, adjusted to the focus of the research, allowed a graphic presentation of the results on pie-charts. They indicate a relatively high precision of measurements of the ultrasonic wave propagation velocity. The lowest variability of $V_{\mathrm{p}}$ values in particular research directions localized on the circumference refer to samples $T$, whereas in the case of the remaining two samples (marked by symbols $\mathrm{F}$ and L), the velocity changes are much larger. Based on these data, the changes of acoustic parameters can be analysed in relation to the accepted research directions (Fig. 5).

Longitudinal ultrasonic waves propagate fastest in directions parallel to lamination: along the longer grain axes and perpendicularly to them. In the latter case, slightly lower values of wave propagation velocities were observed, caused by a higher number of barriers within the rock medium, which led to attenuation of the propagating wave. In turn, in directions perpendicular to lamination and bedding, distinctly lower velocities of the ultrasonic waves were observed. The results of these observations and analyses confirm earlier investigations [4], [5]. The observed anisotropy of the internal structure is emphasized by variability analysis of the obtained velocity results in specific accepted directions. The most common value observed for the direction parallel to the longer grain axes is $4400 \mathrm{~m} / \mathrm{s}$, whereas in the direction perpendicular to the longer grain axes it reaches $4300 \mathrm{~m} / \mathrm{s}$. The most commonly registered $V_{\mathrm{p}}$ values for the direction perpendicular to lamination and bedding reach about $3800 \mathrm{~m} / \mathrm{s}$.

The bi-modal distribution of the longitudinal wave propagation velocity for all measurements obtained in the study reflects distinct anisotropy of the elastic properties in the analysed rock material, which depends on lamination.

The highest point load strength exceeding 7.0 MPa was noted in samples with grain axes perpendicular to lamination and bedding. For the remaining two sample types, the value of this parameter was similar, between 6.3 and $6.9 \mathrm{MPa}$.

Following microscopic analysis of thin sections it was noted that in the case of two out of three samples (with axes parallel to bedding and lamination and perpendicular to the longer axes of mineral grains, and with axes parallel to bedding and lamination and parallel to longer axes of mineral grains), the fracturing process was intergranular, with shear as the dominating mechanism. The third sample (axis perpendicular to bedding and lamination) was characterized by intragranular fracturing, caused by expansion of particular grains. In this case, the key role in inducing the stress field was played by high-resistance grains (quartz grains). Each of the samples differed in the course and geometric properties of the resulting fracture (Fig. 6).

In the case of sample $\mathrm{T}$, the fracture margins are irregular. On both sides of the fracture there occur high-resistant quartz grains which were torn apart due to extension. In some places within the fracture occur small fragments of the rock material, pointing to the fast rate of fracture propagation. Sample L is characterized by the presence of microfractures in close vicinity of the main fracture. These microfractures 
propagated parallel to the main fracture which contains rock fragments. The fracture margin of sample $\mathrm{F}$ is characterized by a similar regularity as sample $\mathrm{L}$, the fracture filling contained fragments of mineral grains and matrix, but the sample lacked microfractures in close vicinity of the main fracture.

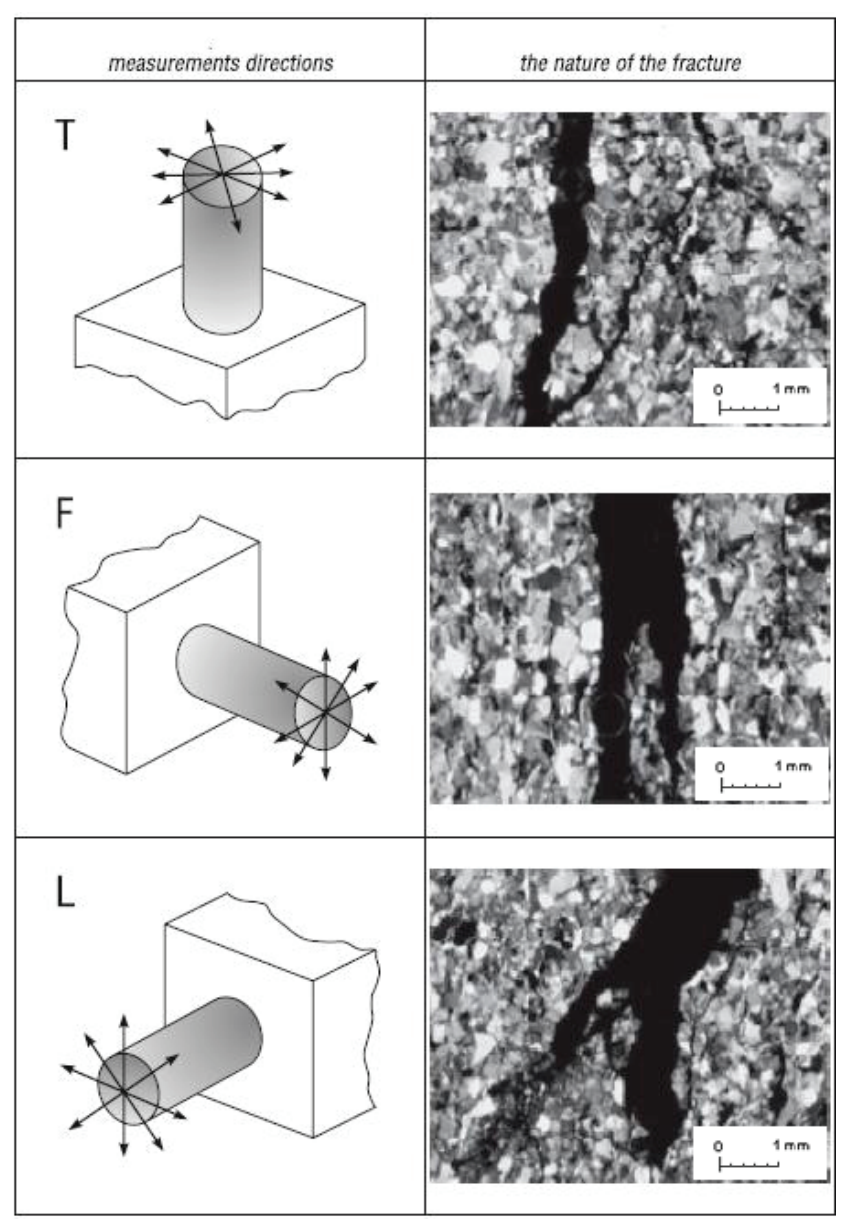

Fig. 6. Differences in the course and geometric properties of the resulting fracture based on orientation of the structural features

Table 2. Statistical parameters describing surface roughness for the Krosno Sandstones of Mucharz

\begin{tabular}{|c|c|c|c|c|c|c|}
\hline $\begin{array}{c}\text { Sample } \\
\text { parameter }\end{array}$ & $\mathrm{T}_{3}$ & $\mathrm{~T}_{4}$ & $\mathrm{~L}_{2}$ & $\mathrm{~L}_{4}$ & $\mathrm{~F}_{1}$ & $\mathrm{~F}_{3}$ \\
\hline$S_{\mathrm{a}}[\mathrm{mm}]$ & 0.48 & 0.57 & 0.36 & 0.65 & 0.46 & 0.21 \\
\hline$S_{\mathrm{q}}[\mathrm{mm}]$ & 0.60 & 0.72 & 0.49 & 0.79 & 0.55 & 0.27 \\
\hline$S_{\mathrm{ku}}[\mathrm{mm}]$ & 3.77 & 3.11 & 5.06 & 3.24 & 2.31 & 2.98 \\
\hline$S_{\mathrm{p}}[\mathrm{mm}]$ & 6.40 & 4.28 & 1.09 & 3.58 & 1.46 & 0.68 \\
\hline$S_{\mathrm{v}}[\mathrm{mm}]$ & 1.37 & 2.28 & 2.14 & 1.78 & 1.57 & 1.11 \\
\hline$S_{\mathrm{t}}[\mathrm{mm}]$ & 7.77 & 6.56 & 3.23 & 5.36 & 3.03 & 1.79 \\
\hline
\end{tabular}

A set of parameters was obtained for each sample after the analysis. They are presented in Table 2 (all values in millimetres).
In the case analysed, the arithmetic mean of absolute values of roughness $\left(S_{\mathrm{a}}\right)$ shows rather low variability within different groups of samples. Also in this case the values of the root mean squares of roughness deviation $\left(S_{\mathrm{q}}\right)$ are characterized by low variability within different groups of samples and usually about $20-30 \%$ larger than $S_{a}$. However, it is not possible to verify whether increase of the $S_{\mathrm{q}}$ value is caused by increased number of peaks or cavities.
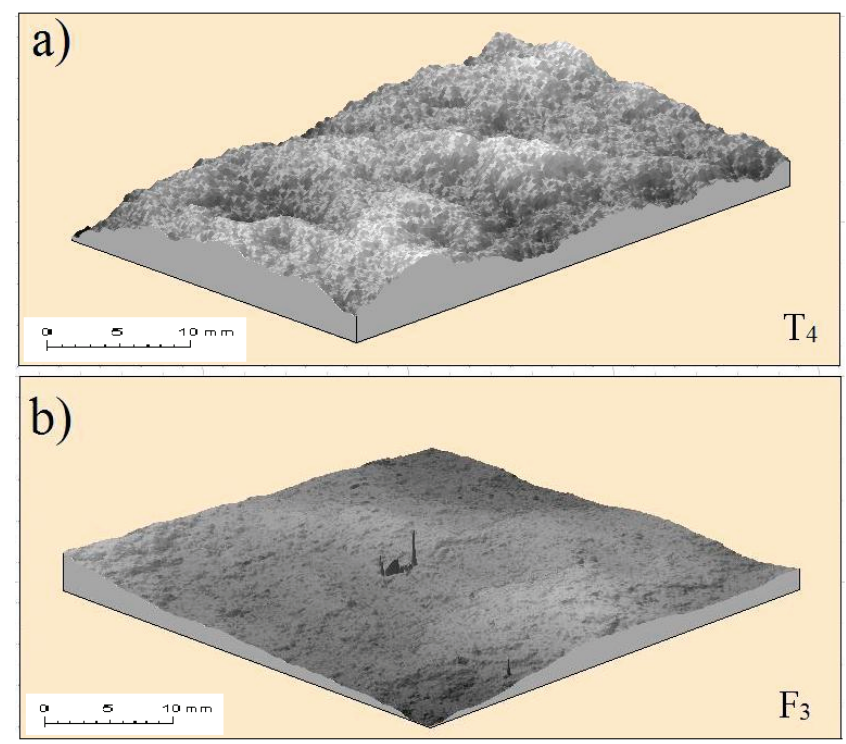

Fig. 7. Visualization of the differences of the roughness between two cleaved surfaces

For sandstone samples $\mathrm{T}$ and $\mathrm{L}$, the value of kurtosis $\left(S_{\mathrm{ku}}\right)$ exceeds 3.0. An $S_{\mathrm{ku}}$ value of 3 indicates normal distribution of the profile elevation values in the sample analysed. Values below 3 point to flattened distribution, linked with the presence of numerous, more rounded peaks and valleys in the profile. $S_{\mathrm{ku}}$ exceeding 3 suggests a more smooth distribution (surfaces with sharp peaks). The highest values of parameter $S_{\mathrm{p}}$ have been determined for samples T, indicating surfaces with sharp peaks. A similar case occurs with the depth of the deepest cavities $\left(S_{\mathrm{v}}\right)$ on the analysed surface. In this case, the highest values of index $S_{\mathrm{y}}$ have been observed in samples T and L. This causes that the highest values of parameter $S_{\mathrm{t}}$, which is the sum of the highest peak and the deepest valley on the analysed surface (total height of the roughness surface), describe also surfaces of samples $\mathrm{T}$ (with axes perpendicular to bedding and lamination). Roughness differences in two surfaces are visualized in Fig. 7. 


\section{CONCLUSIONS}

The assumed goals were accomplished by conducting a series of laboratory analyses combined with analysis of literature data. Ultrasonic and strength investigations, as well as microscopic observations of thin sections, supported by contact profilometry, allowed valuable data to be obtained on the influence of the internal structure and fracture mechanisms on surface roughness of the Krosno Sandstones from Mucharz.

The analyses were conducted on samples of sandstones with variable internal structure, and thus characterized by diverse directional variability of particular physical-mechanical parameters. Results of the analyses have confirmed the existence of anisotropy in the analysed rock material. Anisotropy of the internal structure influences the mechanisms, course and dynamics of the fracturing processes. Due to inhomogeneous internal structure, preferential directions and destruction planes are formed in the rock medium; they result in micro- and macrofractures characterized by high geometrical variability conditioned by the properties of the medium in which they propagate.

Analysis of the results obtained indicates that there is a direct dependence of the destruction process and the internal structure of the rock medium. Macro- and microscopic structural and textural features influence the character and course of the fractures developed due to the action of external forces. Analysis of microfractures in thin sections indicates that the fractures are intergranular (occur between the grains) and rather wide in planes parallel to lamination and bedding. In this case the development of the fracture was stable, controlled and favoured by loose grain distribution. In the case of samples with such fractures the fracture propagated using less resistant zones, e.g., voids between grains filled with the clay-carbonate matrix, weaker than the surrounding grains. In a plane perpendicular to bedding and lamination the fracture is intragranular. This is caused by the fact that extension mechanisms of particular grains predominate over shear mechanisms. The propagating fracture develops in a plane perpendicular to the grain axes and cuts them transversely. The fracture margins are irregular and the fractures contain a certain amount of crushed, small rock fragments. This indicates fast and rapid rate of fracture propagation.

Structural features and the mechanism and course of fracturing processes influences the spatial distribution of fractures differing in surface roughness parameters. Analysis of the obtained data allows us to confirm that the geometrical and morphological parameters of the fractures mostly depend on anisotropy of internal structure and on the mechanism and course of the fracturing process. The results indicate that surface roughness is influenced by lamination and direction of mineral grain distribution. The largest roughness is observed on surfaces perpendicular to lamination and bedding, characterized by intragranular fracturing. This is caused, e.g., by fast and rapid development of the propagating fracture, the presence of numerous barriers along its course and the predomination of extension mechanisms of mineral grains (mainly in resistant quartz grains). The smallest roughness is noted in surfaces parallel to lamination and bedding and parallel to the longer axes of mineral grains (intergranular fracturing). In this case, the fracture propagates slowly, stably and in a controlled mode, and the dominating destruction mechanism is extension.

The analyses also evidence that studies of surface roughness of the cleaved rock media can be successfully conducted using contact profilometry. It determines the statistical parameters describing surface roughness, as well as visualizes and interprets spatial variability of the rock fracturing process. However, all statistical parameters used in this paper supply a quantitative analysis of surface roughness for samples with the same dimensions. Such restriction causes that correct characteristics of surface roughness for samples of different size require application of a different methodology, e.g., fractal analysis.

Surface roughness significantly influences friction forces that affect shear forces and quasi coherence of the discontinuity surfaces, and in the rock massif - susceptibility to block movements [11]. Knowledge of such properties of discontinuous rock media is of high cognitive and practical significance, allows characterizing the degree of fracturing and determining the favoured direction of rock massif disintegration [3]. Analysis of surface roughness of rock material gives assumptions on the origin of the fractures. Therefore, surface morphology should be taken into account in the process of geotechnical assessment of a rock massif. This is important in determining the degree of safety in geoengineering investments in rock media.

\section{REFERENCES}

[1] BoBrowskA A., Badania ultradźwiękowe $w$ ocenie deterioracji skat, Geologia. Kwartalnik Akademii Górniczo-Hutniczej, 2009, 35(2/1), 633-639. 
[2] Domonik A., Textural rock anisotropy as a result of load memory exemplified by Cergowa sandstones from Komańcza, Geologija - Vilnius, 2008, 50, 121-125. DOI: 10.6001/geologija.v50ipriedas.1572.

[3] DOMONIK A., Wtaściwości wytrzymałościowe i odksztatceniowe skat. Część VI. Centralne Karpaty zachodnie, t. 13 and t. 14, Warsaw, Poland: Zakł. Geomech. IHiGI. Wyd. Geol. UW, 2012.

[4] DZIEDZIC A., Structural control on fracture toughness (brittle cracking) in the Krosno Sandstones of Mucharz, southern Poland, Geological Quarterly, 2003, 47, 21-28.

[5] DZIEDZIC A., Ocena cech strukturalnych piaskowców krośnieńskich z Mucharza (Beskid Mały) na podstawie pomiarów prędkości ultradźwiękowej fali podtużnej, Przegląd Geologiczny, 2005, 53(7), 601-604.

[6] ŁUKASZEWSKI P., Odkształcalność piaskowców fliszowych $w$ złożonym stanie naprężeń, Wyd. UW, Warsaw, Poland, 2013.

[7] PINIŃSKa J., Procesy kruchego pękania w skatach osadowych przy jednoosiowym ściskaniu ze stata prędkościq odksztatcania, Przegląd Geologiczny, 1995, 43(7), 546-553.
[8] Pinińska J., PŁatek P., Badania ultradźwiękowe $w$ ocenie wytrzymałości skat, Górnictwo Odkrywkowe, 2002, 44(2/3), 89-96.

[9] PINIŃSKA J., Właściwości wytrzymałościowe i odksztatceniowe skat. Część IV. Karpaty Fliszowe, t. 7. Katalog, Zakł. Geomech. IHiGI. Wyd. Geol. UW, Warsaw, Poland, 2003.

[10] PINIŃSKa J., Właściwości wytrzymałościowe $i$ odkształceniowe skat. Część IV. Karpaty Fliszowe, t. 8. Objaśnienia i interpretacja, Zakł. Geomech. IHiGI. Wyd. Geol. UW, Warsaw, Poland, 2004.

[11] PINIŃSKA J., DZIEDZIC A., Właściwości wytrzymałościowe $i$ odksztatceniowe skat. Część V. Region lubelski. t. 10. Objaśnienia i interpretacje, Wyd. Geol. UW, Warsaw, Poland, 2007.

[12] Pininska J., DzIEDZIC A., Volume density and longitudinal wave velocity changes of the Ciezkowice and Krosno flysch sandstones under high pressure and temperature in the triaxial test condition, Archives of Civil Engineering, 2011, 57(1), 73-85. 